\title{
Tumour-infiltrating lymphocytes in the risk stratification of squamous cell carcinoma of the head and neck
}

\author{
$\mathrm{T}$ M Jones ${ }^{\star}, 1$ \\ ${ }^{1}$ Liverpool CR-UK Centre, Department of Molecular and Clinical Cancer Medicine, University of Liverpool, Liverpool L3 9TA, UK
}

Squamous cell carcinomas of the head and neck (SCCHN) comprise a group of tumours that originate from the epithelium of distinct anatomical regions of the upper aerodigestive tract. National data (http://info.cancerresearchuk.org/cancerstats/types/), arbitrarily divides SCCHN into laryngeal and oral cancer, the latter comprising a heterogeneous group of tumours including lip, tongue, mouth, oropharynx, piriform sinus, hypopharynx and other sites.

During 2010 in the UK, 2337 patients were diagnosed with laryngeal carcinoma and 6539 with oral cancer, accounting for $0.7 \%$ and $2.0 \%$ of the non-melanomatous squamous carcinoma (NMSC) burden, respectively. Thus in the UK $\sim 8500-9000$ cases of SCCHN are diagnosed per annum.

In comparison, Ferlay et al (2010) estimate that worldwide approximately half a million new cases of SCCHN are diagnosed annually.

Globally, therefore, head and neck cancer constitutes a major disease burden in typically highly dependent, low socio-economic class populations who appear to suffer disadvantageous survival outcomes when compared with patients from higher socioeconomic groups, even in a socialised health-care setting such as the UK (Rachet et al, 2008).

Oral cancer is the 11th and larynx cancer the 18th most common cancer presenting in men in the UK. For larynx cancer, this amounts to a modest reduction of cases diagnosed in men when comparing the 3-year cohorts 1997-1999 and 2006-2008. No similar reduction has been seen in cases diagnosed in women. In contrast, since the late 1970s, there has been an exponential increase in the year-on-year incidence of oral cancer: from $7 / 100000$ in 1975 to $12 / 100000$ in 2009 .

While alcohol and tobacco use have long been well documented as individual or synergistic risk factors for the development of SCCHN, over the last three decades evidence has accumulated confirming human papilloma virus (HPV) - genotype 16-as an additional, independent, risk factor for the development of oropharyngeal squamous cell carcinoma (HPV 16 + ve OPSCC;
Bouvard et al, 2009). Consequently, much of the increased incidence of oral cancer reported over recent decades is considered to be due to the global increased incidence of HPV $16+$ ve OPSCC (Mehanna et al, 2013).

Despite being grouped as a single entity, marked biological variability and response to treatment is seen, not only between tumours from different anatomical regions but also between tumours from the same anatomical region. This variable response, and its correlation with poorer survival, is inversely related to the size of the primary tumour and the presence and volume of metastatic disease in the cervical lymph nodes: in particular whether there is pathological evidence of tumour spread through the lymph node capsule (ECS). This clinical variability has been exacerbated over recent decades by the emergence of HPV $16+$ ve OPSCC.

HPV $16+$ ve OPSCCs present a clinical conundrum as they occur in younger, non-smoking and non-heavy drinking individuals, and typically exhibit clinicopathological evidence of aggressive tumour behaviour. However, they ultimately respond better to conventional treatments than their HPV - ve counterparts, Fakhry et al (2008) and Ang et al (2010). Why this is the case has yet to be established. One theory, among several proposed, is that tumour-infiltrating lymphocytes (TILs) may facilitate an enhanced adaptive host immune response against viral antigens (Albers et al, 2005).

Despite this, current 'standard' treatments-which in the Most Developed Countries typically involves cisplatin-based chemotherapy delivered concurrently with external beam radiotherapy (RT) - while conferring improved survival outcomes, may result in significant numbers of patients suffering from disabling long-term swallowing problems (Patterson et al, 2013), although contemporary RT techniques have been shown to result in markedly improved swallowing function (Feng et al, 2010).

In contrast, despite advances in surgical and non-surgical treatments, the overall 3-5-year survival rates for patients presenting with HPV - ve SCCHN remains resistant to improvement at 50-60\%, Fakhry et al (2008) and Ang et al (2010). 
Therefore, the clinical challenge for patients with SCCHN is to develop treatments that enhance survival for patients with HPV - ve tumours, and that maintain the current advantageous survival rates while reducing the severe early and long-term treatment-related toxicities experienced by patients with HPV $16+$ ve OPSCC.

The existence of differential risk groups of SCCHN patients was convincingly demonstrated by Ang et al (2010). Although they showed overall that patients presenting with HPV $16+$ ve OPSCC were at a lower risk of death than patients with HPV - ve tumours, they also demonstrated, following recursive-partitioning analysis of the data, the existence of three apparently distinct risk groups: lowrisk patients included non-smokers with HPV $16+$ ve tumours and low nodal volume disease; intermediate-risk patients were smokers ( $\geqslant 10$ pack years), with $\mathrm{HPV}+$ ve tumours and N2b/N3 nodal disease or non-smokers with T2 or T3 HPV - ve tumours, whereas, high-risk patients were smokers with HPV - ve tumours.

It follows, therefore, that stratifying according to HPV 16 positivity is too simplistic an approach and this is particularly pertinent if de-intensified treatments are sought for patients with HPV $16+$ ve tumours, as inadequate risk stratification will inevitably result in under treatment.

Similarly, additional risk stratification based on smoking history will also not suffice as in practice it will lack the necessary accuracy. Thus, there is an urgent need to strive to discover more robust biomarkers of outcome in patients presenting with SCCHN.

It is to this end that two articles published in this edition are particularly welcome.

Balermpas et al (2014), using immunohistochemistry (IHC) correlated the expression of $\mathrm{CD} 3^{+}, \mathrm{CD}^{+}, \mathrm{CD} 4^{+}$and $\mathrm{FOXP} 3^{+}$ TIL with clinical outcome in the pre-treatment biopsy specimens of 101 patients presenting with advanced stage SCCHN who were treated with concurrent chemoradiotherapy (CRT) and followed up for a mean of 25 months (2.3-63 months). Of this cohort, $20 \%$ presented with tumours of the oral cavity, $31 \%$ of the hypopharynx, $7 \%$ of the larynx and $42 \%$ of the oropharynx. On the basis of positive expression of $16^{\mathrm{INK} 4 \mathrm{a}}, 27.7 \%$ of tumours were considered HPV16 + ve and 72.3\% were considered HPV - ve. Following multivariate analysis, a significant increase in overall survival (OS), progression-free survival (PFS) and distant metastasis-free survival (DMFS), but not local failure-free survival (LFFS), was correlated with high expression of CD3 and CD8. In contrast, neither CD4 nor FOXP3 expression was correlated with clinical outcome. Interestingly, no significant correlation between any of the four TIL markers and outcome was demonstrable for patients with $\mathrm{p} 16^{\mathrm{INK} 4 \mathrm{a}}$-positive tumours.

Similarly, Ward et al (2014), again using IHC, correlated the level of TIL in OPSCC samples of 270 patients presenting to three UK centres with clinical outcome. All patients had been followed for a minimum of six months. Of the included patients, $54.4 \%$ were categorised as HPV + ve on the basis of p16 ${ }^{\mathrm{INK} 4 \mathrm{a}}$ expression and positive in-situ hybridisation staining for at least 1 of 13 high-risk HPV genotypes. Of this HPV + ve group, 55 were treated with surgery (78\% with post-operative radiotherapy), 65 with CRT and 24 with RT alone. In contrast to Balermpas et al (2014), they demonstrated that aggregate TIL level (rather than levels of individual T-cell subsets) was highly correlated with diseasespecific survival (DSS) and PFS in patients with $\mathrm{HPV}+\mathrm{ve}$ tumours. Patients with $\mathrm{HPV}+\mathrm{ve} / \mathrm{TIL}_{\text {low }}$ tumours had similar DSS and PFS to HPV - ve patients, whereas patients with HPV + ve tumours scored as having moderate and high TIL levels enjoyed a $49 \%$ and $79 \%$ reduction in OPSCC mortality, respectively, compared with patients with HPV - ve tumours. However, TIL level was not predictive of outcome in patients with HPV - ve tumours and neither was TIL level correlated with smoking history-a previously demonstrated predictor of outcome in this patient group (Ang et al, 2010).
Although the inevitable conclusion from both of these studies remains that the approaches they outline require standardisation and testing in adequately powered randomised controlled clinical trials, they provide enough promise to warrant doing so. Although it is unlikely that the simple measurement of TILs will provide sufficient accuracy on its own to direct treatment stratification and treatment change, it is only by pursuing these promising avenues of research will we understand the subtleties of solid tumour immunologic responses, from which we will be able to develop strategies that will allow us to incorporate intra-tumoural TIL analysis in the risk stratification of this highly deserving group of patients. Moreover, it is likely that such research will also reveal potential therapeutic targets that might be exploited following the development of novel treatment strategies.

\section{REFERENCES}

Albers A, Abe K, Hunt J, Wang J, Lopez-Albaitero A, Schaefer C, Gooding W, Whiteside TL, Ferrone S, DeLeo A, Ferris RL (2005) Antitumor activity of human papillomavirus type $16 \mathrm{E} 7$-specific $\mathrm{T}$ cells against virally infected squamous cell carcinoma of the head and neck. Cancer Res 65(23): 11146-11155.

Ang KK, Harris J, Wheeler R, Weber R, Rosenthal DI, Nguyen-Tân F, Westra WH, Chung CH, Jordan RC, Lu C, Kim H, Axelrod R, Silverman CC, Redmond KP, Gillison ML (2010) Human papillomavirus and survival of patients with oropharyngeal cancer. New Engl J Med 363(1): 24-35.

Balermpas P, Michel Y, Wagenblast J, Seitz O, Weiss C, Rödel F, Rödel C, Fokas E (2014) Tumour-infiltrating lymphocytes predict response to definitive chemoradiotherapy in head and neck cancer. Br J Cancer 110(2): 501-509.

Bouvard V, Baan R, Straif K, Grosse Y, Secretan B, El Ghissassi F, Benbrahim-Tallaa L, Guha N, Freeman C, Galichet L, Cogliano V. on behalf of the WHO International Agency for Research on Cancer Monograph Working Group (2009) A review of human carcinogens-part B: biological agents. Lancet Oncol 10(4): 321-322.

Fakhry C, Westra WH, Li S, Cmelak A, Ridge JA, Pinto H, Forastiere A, Gillison ML (2008) Improved survival of patients with human papillomavirus-positive head and neck squamous cell carcinoma in a prospective clinical trial. J Natl Cancer Inst 100(4): 261-269.

Feng FY, Kim HM, Lyden TH, Haxer MJ, Worden FP, Feng M, Moyer JS, Prince ME, Carey TE, Wolf GT, Bradford CR, Chepeha DB, Eisbruch A (2010) Intensity-modulated chemoradiotherapy aiming to reduce dysphagia in patients with oropharyngeal cancer: clinical and functional results. J Clin Oncol 28(16): 2732-2738.

Ferlay J, Shin HR, Bray F, Forman D, Mathers C, Parkin DM (2010) Estimates of worldwide burden of cancer in 2008: GLOBOCAN 2008. Int J Cancer 127(12): 2893-2917.

Mehanna H, Beech T, Nicholson T, El-Hariry I, McConkey C, Paleri V, Roberts S (2013) Prevalence of human papillomavirus in oropharyngeal and nonoropharyngeal head and neck cancer-systematic review and meta-analysis of trends by time and region. Head Neck 35(5): 747-755.

Patterson JM, McColl E, Carding PN, Hildreth AJ, Kelly C, Wilson JA (2013) Swallowing in the first year after chemoradiotherapy for head and neck cancer: Clinician-and patient-reported outcomes. Head Neck; e-pub ahead of print 18 June 2013; doi:10.1002/hed.23306.

Rachet B, Quinn MJ, Cooper N, Coleman MP (2008) Survival from cancer of the larynx in England and Wales up to 2001. Br J Cancer 99(Suppl 1): S35-S37.

Ward MJ, Thirdborough SM, Mellows T, Riley C, Harris S, Suchak K, Webb A, Hampton C, Patel NN, Randall CJ, Cox HJ, Jogai S, Primrose J, Piper K, Ottensmeier CH, King EV, Thomas GJ (2014) Tumourinfiltrating lymphocytes predict for outcome in HPV-positive oropharyngeal cancer. Br J Cancer 110(2): 489-500.

(c) (i) (2) This work is licensed under the Creative Commons cc) Attribution-NonCommercial-Share Alike 3.0 Unported License. To view a copy of this license, visit http://creativecommons. org/licenses/by-nc-sa/3.0/ 